Article

\title{
Lithium-Ion Battery Cell Cycling and Usage Analysis in a Heavy-Duty Truck Field Study
}

\author{
Pontus Svens ${ }^{1, *}$, Mårten Behm ${ }^{2}$ and Göran Lindbergh ${ }^{2}$ \\ 1 Scania CV AB, SE-151 87 Södertälje, Sweden \\ 2 Department of Chemical Engineering and Technology, Applied Electrochemistry, \\ School of Chemical Science and Engineering, KTH Royal Institute of Technology, \\ SE-100 44 Stockholm, Sweden; E-Mails: behm@kth.se (M.B.); gnli@kth.se (G.L.) \\ * Author to whom correspondence should be addressed; E-Mail: pontus.svens@scania.com; \\ Tel.: +46-8-553-51661; Fax: +46-8-553-82841.
}

Academic Editor: Joeri Van Mierlo

Received: 18 March 2015 / Accepted: 12 May 2015 / Published: 20 May 2015

\begin{abstract}
This paper presents results from a field test performed on commercial power-optimized lithium-ion battery cells cycled on three heavy-duty trucks. The goal with this study was to age battery cells in a hybrid electric vehicle (HEV) environment and find suitable methods for identifying cell ageing. The battery cells were cycled on in-house developed equipment intended for testing on conventional vehicles by emulating an HEV environment. A hybrid strategy that allows battery usage to vary within certain limits depending on driving patterns was used. This concept allows unobtrusive and low-cost testing of battery cells under realistic conditions. Each truck was equipped with one cell cycling equipment and two battery cells. One cell per vehicle was cycled during the test period while a reference cell on each vehicle experienced the same environmental conditions without being cycled. Differential voltage analysis and electrochemical impedance spectroscopy were used to identify ageing of the tested battery cells. Analysis of driving patterns and battery usage was performed from collected vehicle data and battery cell data.
\end{abstract}

Keywords: hybrid electric vehicle; HEV; lithium-ion battery; $\mathrm{d} V / \mathrm{d} Q$; Electrochemical Impedance Spectroscopy (EIS) 


\section{Introduction}

The main reason for hybridization of vehicles is to reduce tail pipe emissions by saving fuel. Passenger cars have previously been the main contributor of tailpipe emissions amongst the transport sector in Europe, but during recent years, trucks have instead become the main contributor. The transport sector is responsible for $28 \%$ of the $\mathrm{CO}_{2}$ emissions in Europe and almost half of those emissions are related to heavy-duty trucks [1,2]. Globally, the transport sector contributes to about $18 \%$ of the total greenhouse gas emissions [3]. In 2007, the European Union agreed on a greenhouse gas emission reduction target, aiming at reaching a $20 \%$ reduction of greenhouse gas emissions from 1990 levels in 2020 [4]. New emission targets have also contributed to more stringent legislation on tail pipe emissions for heavy-duty trucks and buses. Harsher emission legislation and higher customer demands on lower fuel consumption have driven heavy-duty truck and bus manufacturers to introduce hybridized vehicles. However, the additional cost for a hybrid system needs to be low enough to achieve a reasonable payback time for the customer. The high cost of batteries intended for hybrid electric vehicles (HEVs) is a factor that greatly affects the total cost of a hybrid system. The main type of hybrid systems used by vehicle manufacturers today are the parallel hybrid, the serial hybrid, and the power split hybrid systems [5], where the latter one in a simplified way can be regarded as a combination of the first two. The main difference between the parallel hybrid system and the serial hybrid one is that the former has a mechanical connection between the internal combustion engine and the propelling wheels, while the latter has not. Hence, a serial hybrid vehicle needs two electrical motors while the parallel one only needs one. If the battery system in a hybrid vehicle can be charged externally, the vehicle is referred to as a plug-in hybrid [6]. The benefit with this configuration is the possibility to drive on pure electric power and also have the possibility to travel longer distances using the combustion engine when needed.

When designing a hybrid system, fuel consumption, battery cost, and battery lifetime need to be optimized to find a reasonable cost level for both vehicle manufacturers and customers. For example, the battery pack needs to be light enough and have a sufficiently low volume not to influence load capacity of a HEV truck or limit passenger capacity of a HEV bus. In addition, the hybrid strategy needs to provide high enough energy flow through the battery for a variety of driving patterns without sacrificing battery lifetime. Furthermore, the charge and discharge energy efficiency should be as high as possible to maximize the kinetic energy recuperation without sacrificing energy throughput.

It is obvious from the reasoning above that the relationship between several parameters needs to be considered when designing an HEV battery system. One approach to try to fulfil the demands would be to minimize the size of the battery, both regarding dimensions and capacity, and maximize the usage, i.e., allowing large cycle depth and high power. This would reduce the dimensions and the cost of the hybrid system while maximizing the energy throughput. However, this approach may jeopardize long battery lifetime since deep cycling and high power can have a negative impact on battery life. It is hence important to estimate the impact of battery usage on battery life when designing the battery system. Estimating battery lifetime in a real application is a difficult task since the usage will have a more or less large spread between vehicles depending on hybrid vehicle strategy. To handle this, laboratory battery testing could be performed on an estimated worst case scenario to have a marginal for this spread in usage. Estimating battery lifetime from too harsh testing could, however, lead to 
pessimistic battery life estimations, possibly resulting in an unnecessary high cost for the customer. To prevent this, laboratory testing of batteries could be performed using a variety of synthetic driving cycles to mimic real life usage. In addition, an assumption of variations of environmental parameters such as temperature and resting times is also required. Hence, a more accurate way of acquiring battery ageing information would be to collect data from a fleet of HEVs. The drawback of this could be longer test time depending on the yearly covered mileage of the test fleet. However, acquiring battery usage information and battery ageing results from a fleet of HEVs is most likely more time consuming than laboratory testing and not even feasible in an early HEV development stage. With this understanding, we will in this work demonstrate an alternative way of collecting battery usage data including the possibility to monitor battery ageing during field tests on heavy-duty trucks using recently developed test equipment [7]. This test equipment is intended for use on conventional heavy-duty trucks which facilitate access of test vehicles in an early battery development phase. In addition, this test method allows validation of computer modelled battery usage for various real life driving patterns in an HEV environment. With this test method, a larger spread of battery usage should be possible to obtain compared to laboratory testing. The main advantages compared to real heavy-duty HEV testing are lower cost, shorter test time, and availability of test vehicles. In this study, driving patterns and battery usage are analyzed as well as an early stage of battery cell ageing.

\section{Experimental Section}

This field study includes three heavy-duty trucks from the truck and bus manufacturer Scania CV AB (Södertälje, Sweden), each equipped with recently developed test equipment intended for battery cell cycling [7]. Each test set-up contains two battery cells, one that is continuously cycled during the test and one reference cell that is calendar-aged under the same ambient conditions. Cell performance tests can be performed periodically on the test equipment.

Commercially available composite $\mathrm{LiMn}_{2} \mathrm{O}_{4}-\mathrm{LiCoO}_{2} / \mathrm{Li}_{4} \mathrm{Ti}_{5} \mathrm{O}_{12}(\mathrm{LMO}-\mathrm{LCO} / \mathrm{LTO})$ cells with a rated initial capacity of $3.1 \mathrm{Ah}$ and nominal voltage of $2.4 \mathrm{~V}$ were acquired from a reputable supplier for this study. The measured initial capacity for all cells in the study was $3.45 \pm 0.05 \mathrm{Ah}$. All calendar aged reference cells were charged to State of Charge (SOC) $50 \%$ before starting the test and were held at open circuit. The reference cell on Truck 1 self-discharged to SOC $0 \%$ between the intermediate laboratory measurement and the end of the test, while the reference cells on Trucks 2 and 3 self-discharged to around SOC 35\% between the intermediate measurements and the end of the test. The hybrid strategy implemented in the test equipment was developed to be used on hybrid vehicles from Scania CV AB and allows high charge and discharge power and large depth of discharge (DOD) in order to minimize fuel consumption even with a relatively small battery pack. One main characteristic with this hybrid strategy is to allow higher charging than discharging power. Mild hybridization has been found to be the most cost-effective approach for Scania heavy-duty vehicles, as well as a relatively small battery pack. This means that an abundance of braking power is available and that charging power is restricted to the size of the electrical motor or battery limitations.

Cell currents and voltages were measured during the field test as well as cell temperatures. The vehicle speed was received from the vehicle internal communication network. The energy throughput was calculated in real time and stored as a separate parameter. SOC was also calculated based on 
coulomb counting and open circuit voltage measurements. Actual battery capacity was continuously updated from periodically performed capacity tests on-board the vehicles. A flowchart describing the data collection process during the field test is presented in Figure 1.

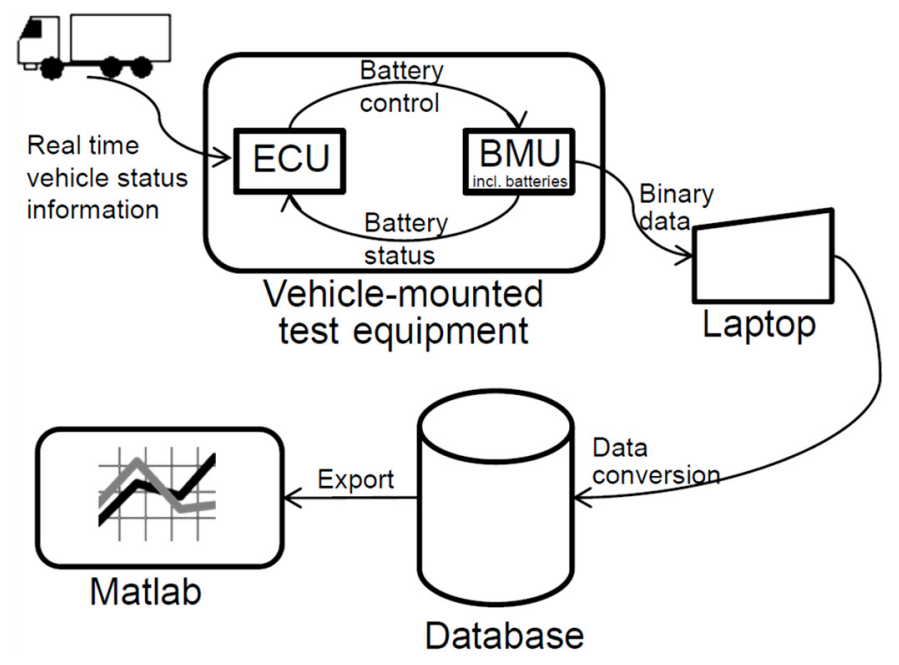

Figure 1. Flowchart describing the field test data collection. The electronic control unit (ECU) communicates with the vehicle and calculates and sends cell cycling data to the battery management unit (BMU). The cycled cell and the reference cell are physically placed in the vicinity of the BMU.

To obtain information about the internal electrode matching of this cell type, one completely discharged fresh cell from a different batch but of the same generation as the tested cells was opened in an argon-filled glove box $\left(<1 \mathrm{ppm} \mathrm{H}_{2} \mathrm{O}\right)$. Samples from both electrodes were collected by cutting out circular pieces of $9.6 \mathrm{~cm}^{2}$. One side of each electrode was cleaned from active material using N-methyl-2-pyrrolidone (NMP) (Merck, Darmstadt, Germany). Care was taken to prevent any NMP from reaching the other side of the electrode during the procedure. The samples were rinsed in dimethyl carbonate (DMC) (SelectiLyte, Merck) and left to dry for thirty minutes before being assembled into cells. Half-cells were made from the positive and negative electrodes, respectively, using lithium foil as references and counter electrode (two electrode cell). Assembly was done together with electrolyte-soaked separator (glass microfiber filter material, Whatman GF/A from Sigma-Aldrich, St. Louis, MO, USA) and nickel and aluminium current collectors. The electrolyte used was $1 \mathrm{M} \mathrm{LiPF}_{6}$ in EC/DEC (1:1 by weight, Merck LP40). The half cells were encapsulated in pouch material (polymer coated aluminium laminate) and vacuum sealed inside the glove box.

Discharge capacity measurements on cells and half cells were carried out using a Solartron SI 1287 electrochemical interface (AMETEK, Berwyn, PA, USA). Discharge capacity was measured at 0.17 A $(\mathrm{C} / 20)$ for the fresh cell prior to opening and at $0.335 \mathrm{~mA}(\mathrm{C} / 20)$ and at $0.27 \mathrm{~mA}(\mathrm{C} / 20)$ for the half cells containing positive electrode samples and negative electrode samples, respectively. All measurements were done at $23{ }^{\circ} \mathrm{C}$. The use of very small currents assured negligible impact of polarization resistance on the voltage profiles. All electrochemical impedance spectroscopy (EIS) measurements were performed on a Solartron SI 1260 Impedance/Gain-phase analyzer (AMETEK, Berwyn, PA, USA). Measurements were performed using a voltage amplitude of $10 \mathrm{mV}$ and a frequency span between $1 \mathrm{kHz}$ and $0.01 \mathrm{~Hz}$. 


\section{Results and Discussion}

\subsection{Driving Pattern and Battery Usage Analysis}

Figure 2 shows distribution plots over vehicle speed, battery cell SOC and battery cell charge and discharge power. Figure 2a shows the vehicle speed distribution for all trucks and it is clear that Truck 1 mostly has been driving at low speeds, typically around $20 \mathrm{~km} / \mathrm{h}$ and very seldomly above $60 \mathrm{~km} / \mathrm{h}$. Two broad peaks are seen around $20 \mathrm{~km} / \mathrm{h}$ and $50 \mathrm{~km} / \mathrm{h}$ and a very small peak around $89 \mathrm{~km} / \mathrm{h}$. This is a typical inner city transportation type of drive pattern. Truck 2 has a relatively even speed distribution up to $60 \mathrm{~km} / \mathrm{h}$, and there are two distinctive peaks around $80 \mathrm{~km} / \mathrm{h}$ and $89 \mathrm{~km} / \mathrm{h}$. Truck 2 spends a large time driving at speeds higher than $60 \mathrm{~km} / \mathrm{h}$ which is reflected in the highest average speed of the three test vehicles. Truck 3 has a similar speed distribution as truck 2 but lacks a peak at around $80 \mathrm{~km} / \mathrm{h}$ and also spends a large part of the driving at speeds below $30 \mathrm{~km} / \mathrm{h}$. This type of driving pattern is typical for intercity transportation where the vehicles are driving both within cities and between cities. The driving pattern for Truck 1 is similar to the City Suburban Cycle (CSC) presented in Figure 2b. The CSC is a chassis dynamometer test for heavy-duty vehicles developed within the West Virginia University [8] and has an average speed of $22.8 \mathrm{~km} / \mathrm{h}$. Truck 2, and to some extent also Truck 3, have a driving pattern similar to the Urban Dynamometer Driving Schedule (UDDS) in Figure 2b. The UDDS was developed for chassis dynamometer testing of heavy-duty vehicles by the US Environmental Protection Agency (EPA) [9]. The average speed for this driving schedule is $30.4 \mathrm{~km} / \mathrm{h}$. Figure $2 \mathrm{c}$ depicts SOC distributions for all three trucks. The cycled cell on Truck 1 shows a Gaussian-like SOC distribution centered around 50\% while the cells on Trucks 2 and 3 show distributions with peaks at SOC levels lower than $50 \%$. The probable cause for this is the driving at higher speeds for Trucks 2 and 3 since the hybrid strategy tends to drive battery SOC towards the lower limit during acceleration. The cycled cell on Truck 1 is seldom discharged to the lower SOC limit at $20 \%$, probably due to relatively short time between acceleration and braking in most cases. The cycled cell on Truck 2 has a distinct high peak at 20\% SOC and a wide peak around 40\% SOC. Frequent highway driving is the probable cause for this. The cycled cell on Truck 3 has a small peak around $20 \%$ SOC but the main distribution is around $30 \%$ SOC. The difference between SOC distributions for the cells on Trucks 2 and 3 can be explained by looking at the corresponding vehicle speed distributions. Truck 2 appears to have been driving frequently on roads where the speed limit changes between $80 \mathrm{~km} / \mathrm{h}$ and $90 \mathrm{~km} / \mathrm{h}$. It is also seen that the peak around $80 \mathrm{~km} / \mathrm{h}$ in the speed distribution plot for Truck 2 actually consists of three peaks. This indicates extensive acceleration and braking even at highway speeds that should have caused cycling of the battery cell to some extent. This could explain the wide peak around 40\% SOC, even though Truck 2 spends the least amount of time driving at low speeds of the three trucks. The sole distinctive peak around $89 \mathrm{~km} / \mathrm{h}$ in the speed distribution plot for Truck 3 indicates that there is only minor acceleration and braking at highway speeds with subsequent minor cell cycling, and this would correlate to the peak at $20 \%$ SOC. 

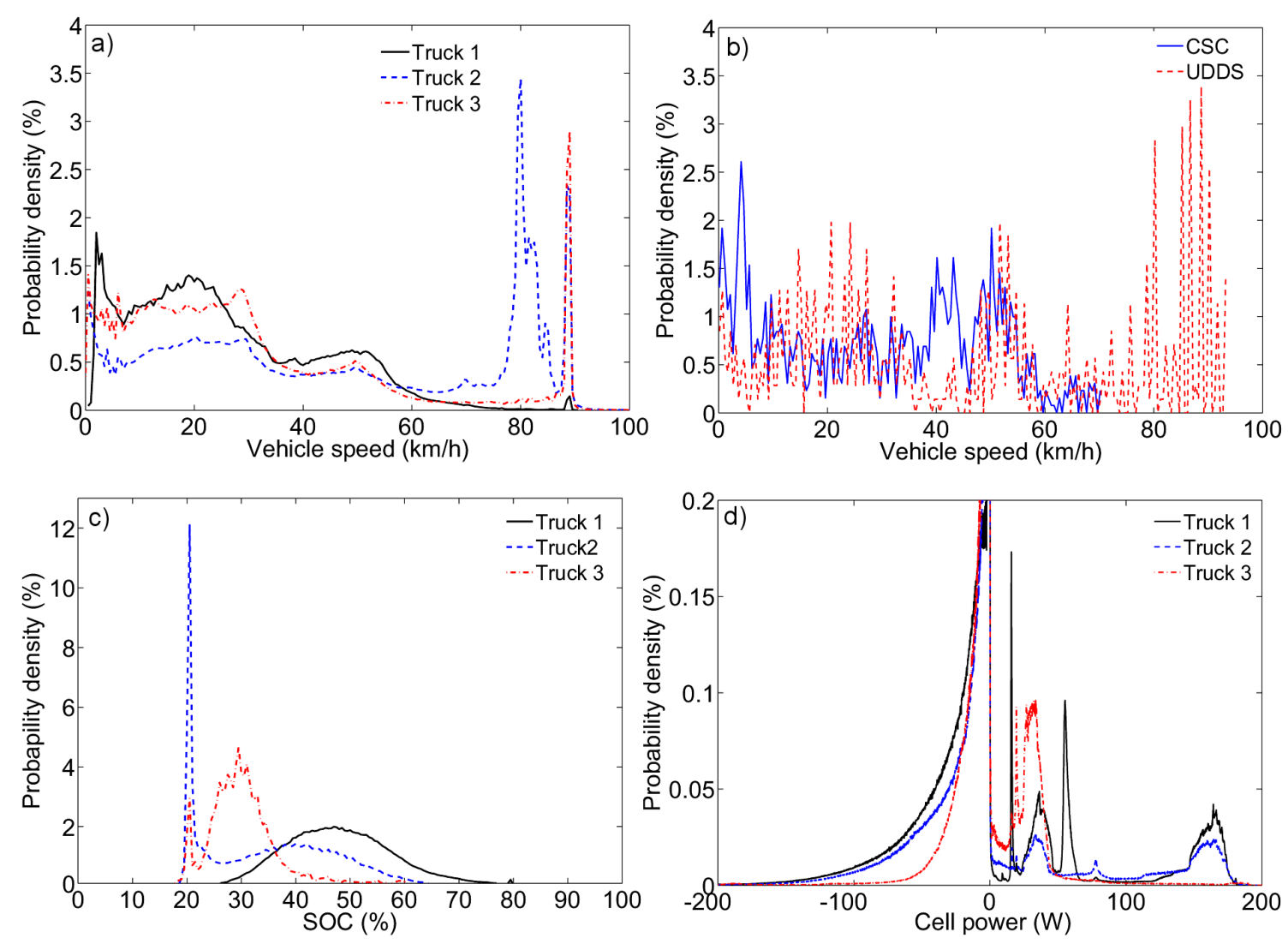

Figure 2. Distribution plots for the complete test period showing: (a) vehicle speed (vehicle idling data excluded for better visibility, resolution $0.5 \mathrm{~km} / \mathrm{h}$ ); (b) vehicle speed for two reference driving schedules; (c) battery cell SOC (resolution $0.5 \%$ ) and (d) battery cell power (resolution $0.1 \mathrm{~W}$, charge power is positive).

Figure $2 \mathrm{~d}$ shows cell power distributions for the trucks. Negative power values correspond to discharging and positive power values to charging. The cell power reflects how the hybrid strategy is controlling the battery cycling. The evaluated hybrid strategy was developed with the assumption that there is an excess of available braking energy in most cases. Hence, the charging and discharging strategies are not the same. The charging power is proportional to the driver-demanded power according to Equation (1):

$$
P_{c h} \propto\left\{\begin{array}{l}
P_{d d} \\
P_{l i m}
\end{array}\right.
$$

$P_{\mathrm{ch}}$ is the charge power and $P_{\mathrm{dd}}$ the driver-demanded power. $P_{\text {lim }}$ is the limiting hybrid system input power that depends on both battery limitations and electric motor limitations. A comparison between $P_{\mathrm{dd}}$ and $P_{\mathrm{lim}}$ is done continuously, and the lowest value is chosen. A proportionality sign in Equation (1) is used since other braking methods such as retarder braking and exhaust braking are also involved when charging the battery. It is clearly seen that the cycled cell on Truck 1, which has a typical inner city transportation driving pattern, has the largest charge power peak around $160 \mathrm{~W}$. This is most probably due to more frequent and harder braking connected to the inner city driving pattern. The cycled cell on Truck 2 also has a distinctive peak at $160 \mathrm{~W}$ while the cycled cell on Truck 3 lacks charge peaks above $35 \mathrm{~W}$. The difference in charge power distribution for the cycled cell on Truck 3 compared to Truck 2 is most likely due to softer braking in the previous case. The weight of the 
vehicles would also affect the charge power since a heavier vehicle would have more kinetic energy requiring harder braking during deceleration, which would generate higher positive power peaks for the tested battery cell. Discharge power distributions for all cycled cells have a smooth appearance connected to the discharge strategy, which is presented below.

$$
P_{d i s c h} \propto \frac{S O C-S O C_{L}}{S O C_{U}-S O C_{L}} \frac{v}{v_{\max }} *\left\{\begin{array}{c}
P_{d d} / 2 \\
P_{\text {lim }}
\end{array}\right.
$$

$P_{\text {disch }}$ is the battery discharge power and $P_{\mathrm{dd}}$ the driver demanded power. $P_{\text {lim }}$ is the limiting hybrid system output power and depends on both battery limitations and electric motor limitations. A comparison between $P_{\mathrm{dd}} / 2$ and $P_{\mathrm{lim}}$ is done continuously, and the lowest value is chosen. SOCu is the upper limit of the SOC window $(80 \%)$ and $\mathrm{SOC}_{\mathrm{L}}$ is the lower limit $(20 \%) . v$ is the vehicle speed and $v_{\max }$ is the maximum allowed vehicle speed $(89 \mathrm{~km} / \mathrm{h})$. It is seen from Equation (2) that the allowed discharge power in general is lower than the allowed charge power. In addition, the discharge power is also scaled by vehicle speed and actual battery SOC. Hence, a high SOC and high vehicle velocity will generate a high discharge power. The vehicle speed scaling factor explains the discharge power peak close to zero that is seen for all cycled cells (truncated in Figure $2 \mathrm{~d}$ for better visibility). This concept results in smooth discharge curves as seen in Figure 2d. Since one main purpose of this study was to evaluate a hybrid vehicle strategy, and since the evaluated hybrid vehicle strategy calculates battery load as the power transferred between the battery system and the power electronics part, we choose to use battery energy throughput (Wh) instead of capacity throughput (Ah) when presenting the results.

Table 1 presents the most important driving pattern and battery usage results from the field test. It is seen from the table that Truck 2 has the highest average speed due to more frequent highway driving compared to Trucks 1 and 3. In spite of this, the cycled cell on Truck 2 was exposed to higher energy throughput per driving distance compared to the cell on Truck 3. This is almost certainly connected to the different type of highway driving Truck 2 has experienced in combination with an overall harder braking pattern, possibly connected to heavier goods transportation. The highest energy throughput per driving distance is found for the cycled cell on Truck 1. This is expected due to the typical inner city transportation driving pattern this truck has experienced. It is also seen in Table 1 that the average cell charge power for all trucks are higher than the average cell discharge power. This is also expected since it is the main characteristic of the tested hybrid strategy. The total travelled distance for each truck during the test period is low but representative for this type of transportation trucks that are only operated during dayshifts and not on weekends. Hence, the equivalent number of full cycles for the battery cells is low even for the cell on Truck 1 that has been cycled for almost two years, and the cycling time is only about $6 \%$ of the total testing time. Thus, calendar ageing has a significant impact on battery pack lifetime for this type of driving and should be addressed in an early phase of HEV development. The average cell temperature is highest for Truck 2, and this is explained by the use of a lower set point for the operating temperature of the battery cells in Trucks 1 and 3 during the early stage of cycling. Since the cycle-aged and the calendar-aged cells on each truck were placed in the same heat conducting holder, each pair of cycle-aged and calendar-aged cell experienced the same temperature distribution during the test. The temperature distributions for each truck are shown in Figure 3. 
Table 1. Key figures from the driving pattern and battery usage analysis.

\begin{tabular}{|c|c|c|c|c|c|c|c|c|c|c|c|c|}
\hline Truck & $\begin{array}{c}\text { Test } \\
\text { Duration }\end{array}$ & $\begin{array}{c}\text { Travelled } \\
\text { Distance/km }\end{array}$ & $\begin{array}{c}\text { Average } \\
\text { Vehicle } \\
\text { Speed/km h }{ }^{-1} \\
\end{array}$ & $\begin{array}{c}\text { Charge } \\
\text { Energy/kWh }\end{array}$ & $\begin{array}{c}\text { Discharge } \\
\text { Energy/kWh }\end{array}$ & $\begin{array}{c}\text { Average } \\
\text { Energy } \\
\text { Efficiency/\% }\end{array}$ & $\begin{array}{l}\text { Total Cycled } \\
\text { Energy/kWh }\end{array}$ & $\begin{array}{c}\text { Equivalent } \\
\text { Number of Full } \\
{\text { Cycles, } \mathbf{N}_{\mathrm{eq}}}\end{array}$ & $\begin{array}{c}\text { Cycled Energy per } \\
\text { Driving Distance/ } \\
\mathbf{W h ~ k m}^{-1} \\
\end{array}$ & $\begin{array}{c}\text { Average } \\
\text { Cell Charge } \\
\text { Power/W } \\
\end{array}$ & $\begin{array}{c}\text { Average Cell } \\
\text { Discharge } \\
\text { Power/W } \\
\end{array}$ & $\begin{array}{c}\text { Average Cell } \\
\text { Temperature } \\
\text { during Cycling } /{ }^{\circ} \mathbf{C}\end{array}$ \\
\hline 1 & 23 months & 25430 & 26 & 12.8 & 12.1 & 94.5 & 24.9 & 1496 & 0.98 & 83 & 26 & 32 \\
\hline 2 & 12 months & 19400 & 47 & 7.26 & 6.94 & 95.6 & 14.2 & 859 & 0.73 & 89 & 18 & 38 \\
\hline 3 & 21 months & 19000 & 30 & 3.49 & 3.44 & 98.6 & 6.9 & 419 & 0.36 & 27 & 9.5 & 31 \\
\hline
\end{tabular}

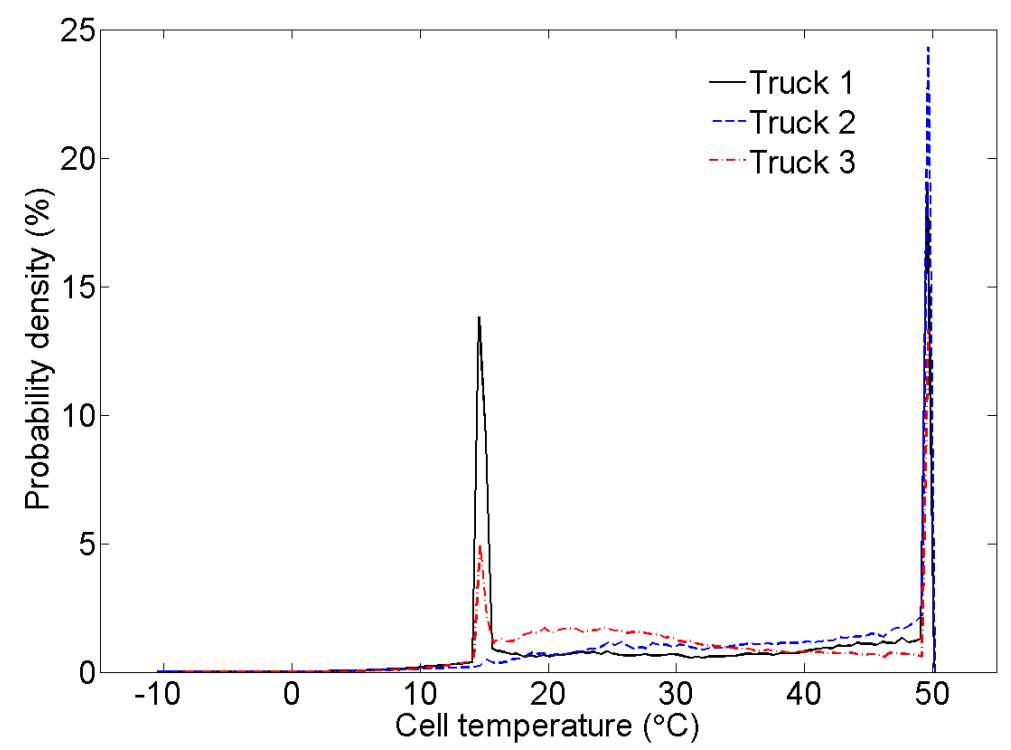

Figure 3. Distribution plots for the complete test period showing cell temperatures (the reference cells have the same distributions at the cycled cells, resolution $0.5^{\circ} \mathrm{C}$ ). 
This test concept should have a great potential for comparing different hybrid strategies in a real application in order to validate simulations. For example, by using a large fleet of vehicles, a large spread of battery usage would give a good input to how different hybrid strategies combined with different battery cells would influence energy throughput. However, evaluation of hybrid strategies with this test concept also has limitations. For example, an HEV could have a different gear-shifting pattern compared to a conventional vehicle, and this is difficult to emulate using this test method.

Validation of battery management strategies such as, for example, SOC estimation and SOC calibration is another possible field of application for this test concept. In this case, the test concept has an additional advantage compared to testing on real HEVs due to its capability to perform periodical SOC calibrations and performance tests during vehicle operation.

\subsection{Capacity Measurements}

Initial discharge capacity for all cells in the field study was measured in the laboratory prior to testing. Capacity measurements were also performed a number of times during the field test. Equivalent full cycles were calculated from the total cycled energy and the initial cell capacity according to Equation (3):

$$
N_{e q}=\frac{W_{t o t}}{2 \cdot U_{n o m} \cdot Q_{\text {init }}}
$$

$N_{e q}$ is the equivalent number of full cycles, $W_{t o t}$ is the accumulated energy throughput for the cycled cell, $U_{\text {nom }}$ is the specified nominal battery voltage and $Q_{\text {init }}$ is the measured initial battery capacity. Figure 4 shows discharge curves from different measurement occasions for the cycle-aged cells, as well as discharge curves for the calendar-aged reference cells.

The cycled cell on Truck 1 experienced a capacity loss of $3.0 \%$ after 1072 equivalent cycles and $6.6 \%$ after 1496 equivalent cycles. The corresponding capacity loss for the reference cell was $1.2 \%$ and $1.5 \%$, respectively. The cycled cell on Truck 2 experienced no capacity loss after 79 cycles but $1.3 \%$ after 859 cycles compared to $0.5 \%$ for the corresponding reference cell at the end of test. The cycled cell on Truck 3 experienced no capacity loss after either 177 or 419 cycles while the corresponding reference cell experienced a capacity loss of $0.5 \%$ at the end of test. 

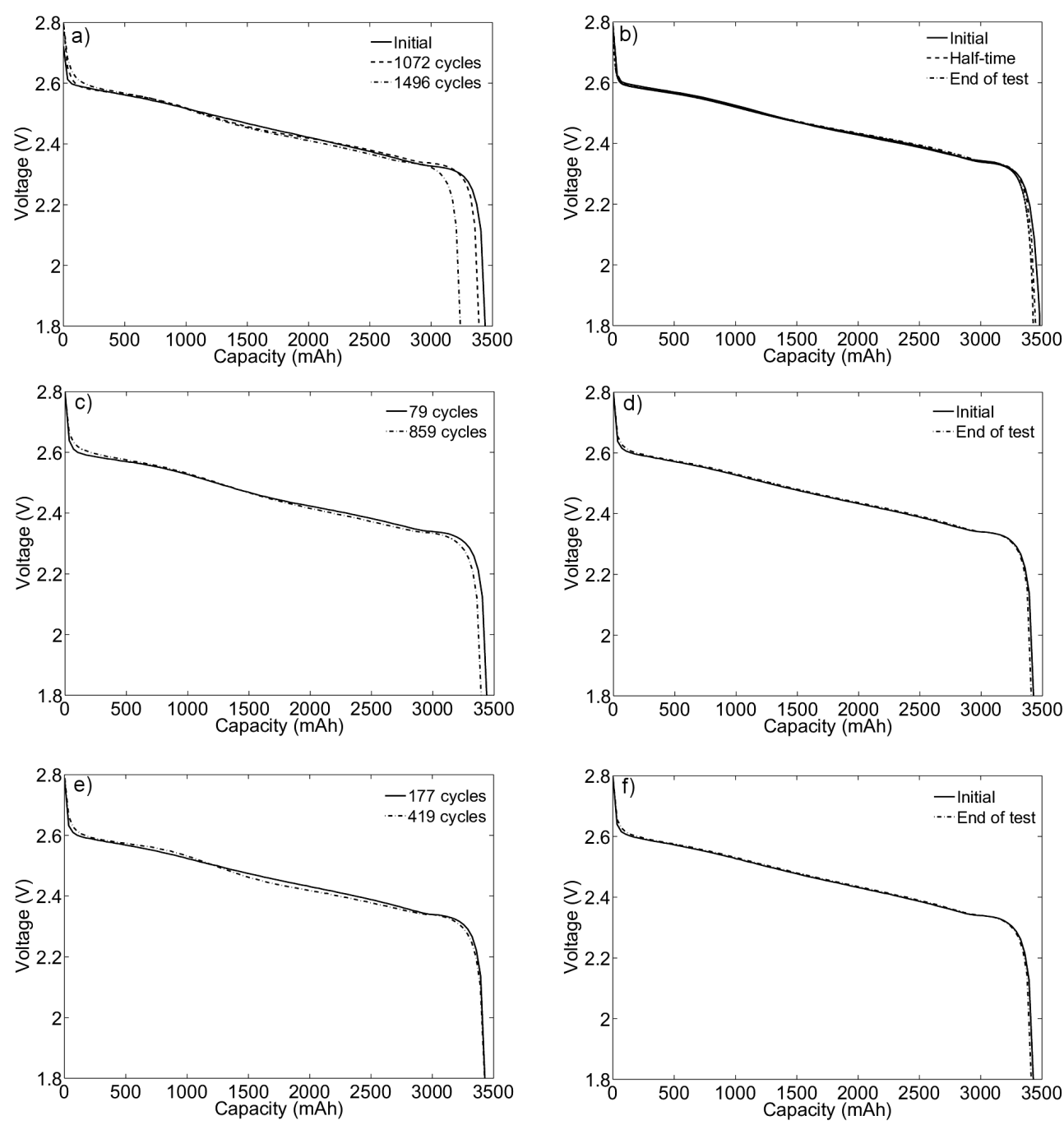

Figure 4. Discharge capacity $(\mathrm{C} / 20)$ at different equivalent cycles $(\mathrm{Neq})$ for $(\mathbf{a})$ cycle aged cell on Truck 1; (b) calendar-aged cell on Truck 1 (half-time corresponds to 1072 cycles for the cycle-aged cell); (c) cycle-aged cell on Truck 2; (d) calendar-aged cell on Truck 2; (e) cycle-aged cell on truck 3 and (f) calendar-aged cell on Truck 3.

\subsection{Differential Voltage Analysis}

This cell type has in a previous study [10] shown that loss of cell capacity mainly correlates to ageing of the positive electrode. The positive electrode contains LMO and LCO active material, which both have been investigated regarding ageing mechanisms in earlier studies [11-14]. The negative electrode active material LTO has a flat discharge curve over almost the complete State of Charge (SOC) range $[15,16]$ resulting in that the differential voltage $(\mathrm{d} V / \mathrm{d} Q)$ curve of the cell will mirror the differential voltage curve of the positive electrode. Hence, $\mathrm{d} V / \mathrm{d} Q$ analysis is a useful method for evaluating ageing of the positive electrode for this cell type. The $\mathrm{d} V / \mathrm{d} Q$ analysis method has been described in our earlier work [10] and in other publications [17-19] and will not be discussed further here. A $\mathrm{d} V / \mathrm{d} Q$ plot for this cell type has two peaks corresponding to phase changes in the positive electrode active material. By analyzing changes in position of the peaks, it is possible to identify ageing of the positive electrode and correlate it to loss of cell capacity. Figure 5 displays $\mathrm{d} V / \mathrm{d} Q$ plots for all cells in the study. 

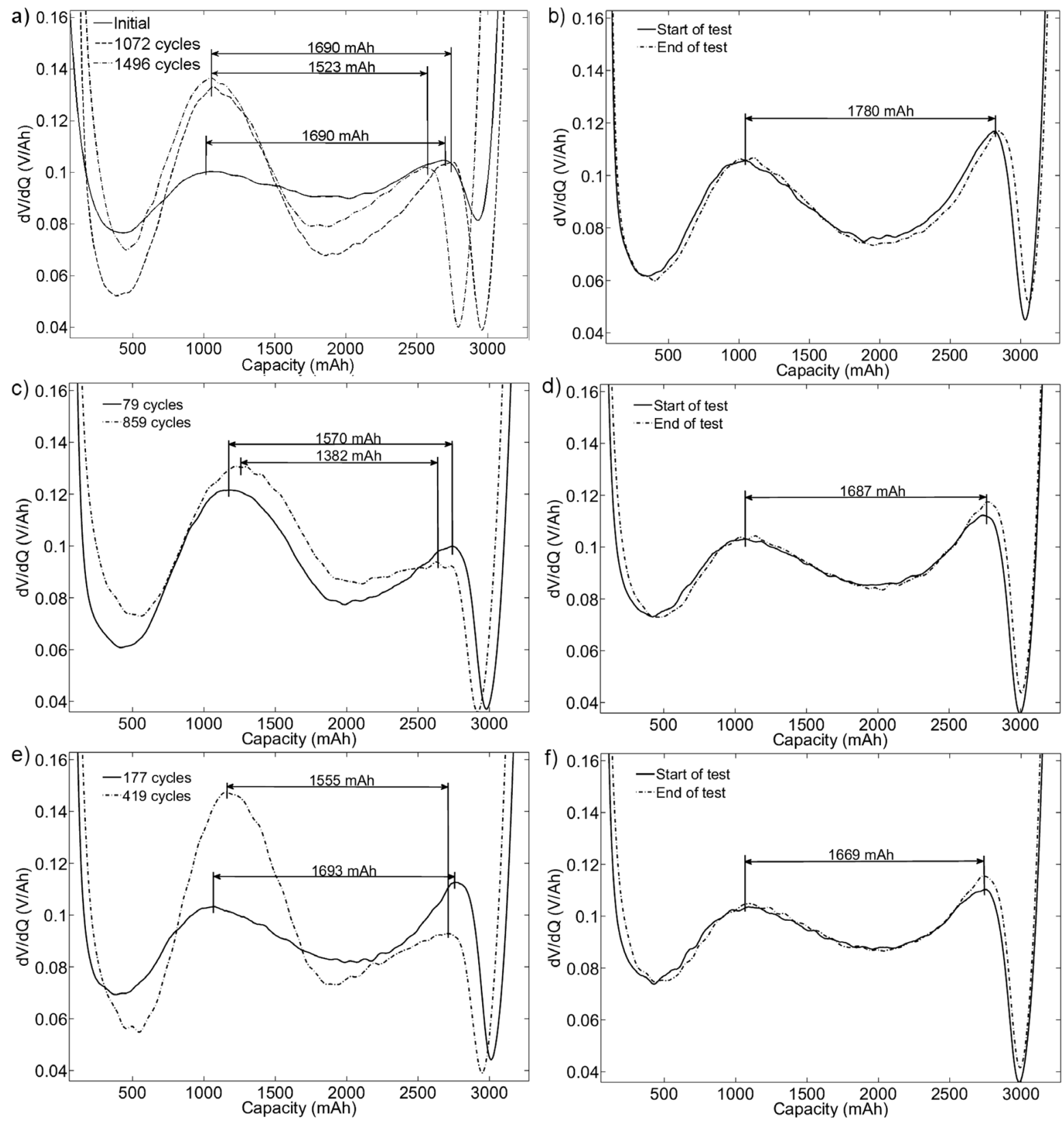

Figure 5. $\mathrm{d} V / \mathrm{d} Q$-plots corresponding to the discharge curves in Figure 4: (a) cycle-aged cell on Truck 1; (b) calendar-aged cell on Truck 1; (c) cycle-aged cell on Truck 2; (d) calendar-aged cell on Truck 2; (e) cycle-aged cell on Truck 3 and (f) calendar-aged cell on Truck 3.

The ratio between the heights of the two peaks in the $\mathrm{d} V / \mathrm{d} Q$ plots in Figure 5 is different for all cycled cells at the end of test compared to the calendar aged reference cells. The effect is also seen for the initial curve compared to the aged curves in Figure 5a. This is a clear indication that all cycled cells have experienced ageing of the positive electrode, even though the discharge capacity for the cycled cell on truck 3 indicates the opposite. The existence of two $\mathrm{d} V / \mathrm{d} Q$ peaks clearly indicates presence of LMO and LCO active material, according to literature [20]. The distance between the peaks correlates to the capacity of the positive electrode so that a larger distance between peaks corresponds to a higher electrode capacity. It is seen in Figure 5a,c,e that the distance between peaks has become smaller between measurement occasions for all cycled cells while no difference is seen for the corresponding 
measurements on reference cells in Figure 5b,d,f. The lower temperature in the early stage of testing for the cycled cells on Truck 1 (Figure 5a) and Truck 3 (Figure 5e) is probably the origin of the difference in $\mathrm{d} V / \mathrm{d} Q$ behavior compared to the cycled cell on Truck 2 (Figure $5 \mathrm{c}$ ). The calendar-aged cells are, however, apparently not affected by this difference in temperature distribution.

This suggests that all cycled cells have experienced a loss of positive electrode active material to some extent, except between the initial measurement and the first 1072 cycles for the cells on Truck 1. However, the cells on Truck 1 experience a change of ratio between the heights of the two peaks in the $\mathrm{d} V / \mathrm{d} Q$ plots during that period. This indicates presence of an ageing mechanism in the early stage of cycling that does not immediately result in capacity loss, possibly related to the composition of the electrode active material. A Scanning Electron Microscopy Energy Dispersive X-ray (SEM EDX)-analysis of fresh positive electrode material (not shown here, more information about the measurement setup can be found in our previous paper [10]) from a cell with the same specification as the tested cells but from a different batch, revealed a higher content of LMO than LCO. Since we in our previous paper [10] found that the LMO active material likely ages faster than the LCO, this could explain the change of ratio between the heights of the two peaks in the $\mathrm{d} V / \mathrm{d} Q$ plots in Figure $5 \mathrm{a}, \mathrm{c}$.

To understand if it is possible to obtain loss of positive electrode active material without observing an influence on the cell capacity, a graphical representation of the electrode matching within the cell is used (Figure 6a). The fitting procedure used is presented elsewhere [10] and includes half cell measurements on both positive and negative electrode material samples collected from a fresh cell from a different batch but of the same generation as the tested cells. $\mathrm{d} V / \mathrm{d} Q$ data from the positive electrode sample are fitted to full cell $\mathrm{d} V / \mathrm{d} Q$ data according to Equation (4):

$$
\frac{d V_{\text {cell }}}{d Q_{\text {cell }}}=\frac{1}{s_{\text {pos }}} \frac{d V_{\text {pos }}\left(s_{\text {pos }} q_{\text {pos }}+\delta_{\text {pos }}\right)}{d q_{\text {pos }}}
$$

The scaling factor is denoted $s$ (unit less) and the capacity for each half cell electrode sample is denoted $q(\mathrm{mAh})$. The shift is called slippage and is denoted $\delta(\mathrm{mAh})$. The calculated open circuit voltage $(\mathrm{OCV})$ curve is in turn obtained by subtracting the negative electrode potential from the positive. However, to get the half-cell OCV-curves to fit the full cell OCV-curves, the $\mathrm{x}$-axis values have to be scaled. In addition, the OCV curves need to be shifted along the x-axis for each electrode relative the full cell OCV, according to Equation (5):

$$
V_{\text {cell }}\left(Q_{\text {cell }}\right)=V_{\text {pos }}\left(s_{\text {pos }} q_{\text {pos }}+\delta_{\text {pos }}\right)-V_{\text {neg }}\left(s_{\text {neg }} q_{\text {neg }}+\delta_{\text {neg }}\right)
$$

The fitting parameters for the fresh cells were calculated to $s_{\text {pos }}=s_{\text {neg }}=636, \delta_{\text {pos }}=20 \mathrm{mAh}$ and $\delta_{\text {neg }}=-32 \mathrm{mAh}$. It is seen in Figure 6a that this cell type has an excess of positive electrode active material and that it is the negative electrode that limits the cell capacity when fully charged. Comparing with an earlier study of this cell type [6], it can be concluded that the main part of the ageing is due to loss of positive electrode active material, resulting in a smaller positive electrode capacity curve in Figure 6a. If only positive electrode active material is lost, the left end of the positive electrode capacity curve will move rightward in Figure 6a while the right end of the curve stays in position. This would result in a simultaneous loss of cell capacity. However, since the loss of positive active electrode material essentially creates an excess of cyclable lithium for this cell type, loss of cyclable lithium in combination with loss of positive electrode active material would instead make the 
right end of the positive electrode capacity curve to move leftward while the left end stays in position. In the latter case, the cell capacity will initially be unaffected since there is an excess of positive electrode active material. This could be the case for the cycled cell on Truck 3 since there is an influence on $\mathrm{d} V / \mathrm{d} Q$ from cycling but not on cell capacity. If both the loss of positive electrode active material and the loss of cyclable lithium are taking place simultaneously, the $\mathrm{d} V / \mathrm{d} Q$-peaks should also move towards each other, which is the case for the cycled cells in Trucks 2 and 3 in Figure 5c,e. However, for the cell on Truck 1 , the $\mathrm{d} V / \mathrm{d} Q$ curve at 1496 cycles seems to have shifted to the left compared to the previous measurement, indicating that only positive electrode active material has been lost in this case. This suggests that this cell type experiences both a loss of positive electrode active material and a loss of cyclable lithium in the beginning of cycling. During further cycling, loss of cyclable lithium seems to gradually decrease while the loss of positive electrode active material seems to continue. Hence, the initial excess of positive electrode active material seen for this cell type is not possible to fully access due to this increasing surplus of cyclable lithium relative to the positive electrode. This virtual surplus of cyclable lithium is generated when the amount of lost positive electrode active material exceeds the loss of cyclable lithium and at this point the peaks in the $\mathrm{d} V / \mathrm{d} Q$-plot should start to move leftwards, while also decreasing the distance between peaks.

a)

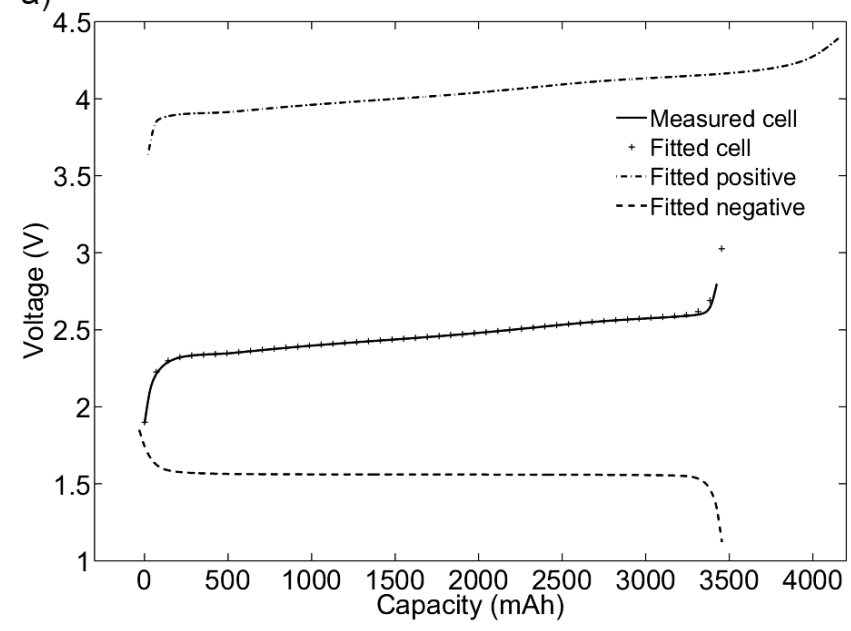

b)

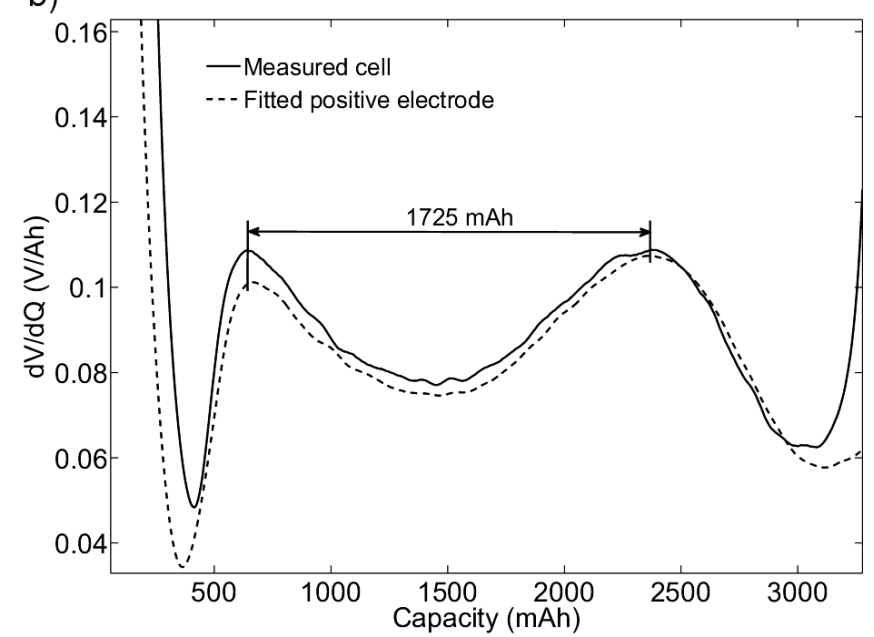

Figure 6. (a) Internal cell matching for a fresh cell. (b) Fitted positive electrode $\mathrm{d} V / \mathrm{d} Q$-data to full cell $\mathrm{d} V / \mathrm{d} Q$-data.

\subsection{Impedance Measurements}

Impedance measurements were performed on all cells in the test and the results are presented in Figure 7.

The most visible change in impedance is a growth of the semicircle and a shift to the right in the Nyqvist plot for all cycled cells. This trend is in line with our earlier findings for this cell type and is most probably connected to the positive electrode. There is an initial difference in low frequency impedance behaviour between the cells on Truck 1 and the cells on Trucks 2 and 3. One explanation to this could be that the initial impedance measurement on the cells on Trucks 2 and 3 were performed five months later than the initial impedance measurement on the cells on Truck 1. This would then imply that there is an initial calendar ageing effect on the low frequency impedance for this type of 
cells, followed by a calendar ageing effect also influencing the impedance at higher frequencies, according to Figure 7.
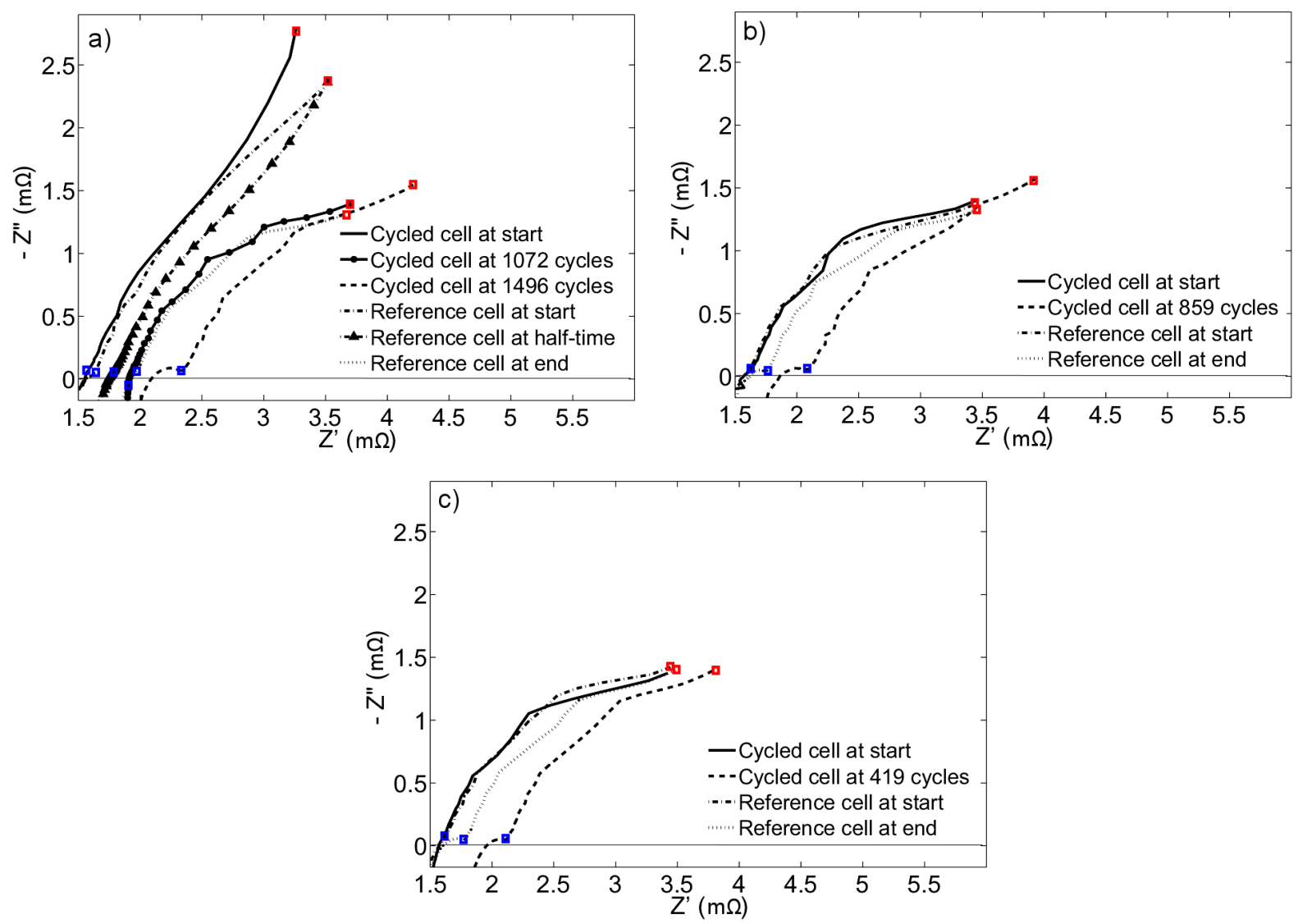

Figure 7. Nyquist plots at SOC $50 \%$ and $23{ }^{\circ} \mathrm{C}$ for both cycled and calendar-aged cells. Blue square markings represent $1 \mathrm{~Hz}$ and red represents $0.01 \mathrm{~Hz}$. (a) Cells from Truck 1; (b) cells from Truck 2; (c) cells from Truck 3.

\section{Conclusions}

In this study, lithium-ion battery cells were cycled and data was collected from three heavy-duty Scania trucks using in-house developed test equipment. Driving patterns were analyzed and verification of hybrid strategy functionality was performed. SOC and power distributions were analyzed to show how battery usage depends on driving pattern.

A comparison of capacity reduction between cycle-aged cells and calendar-aged cells was made. The cycle-aged cell on Truck 1 experienced 1496 corresponding full cycles and a total capacity loss of $6.6 \%$. The corresponding calendar-aged cell lost $1.4 \%$ of the initial capacity during the same test period. The cells from the two other trucks in the study showed smaller differences between cycle-aged and calendar-aged cells. The capacity fade and impedance rise was found to be related to the positive electrode. The probable cause for capacity fade for this type of battery cell is loss of positive electrode active material in combination with excess of cyclable lithium relative the positive electrode. The difference in cell temperature distribution between the three trucks in the study should only have a minor impact on ageing since no significant difference in calendar ageing were seen for the reference cells. This implies that the ageing of the cycled cells mainly is caused by usage, not temperature differences. 
Vehicle speed distribution plots revealed inner city and intercity transportation types of driving. The relatively low yearly mileage coverage supports this statement. The energy throughput per driving distance was as expected highest for the truck driving exclusively in city traffic. A high energy throughput per driving distance was however also obtained for Truck 2 that during a large part of the test period was driving at highway speeds.

This study has shown that the described single battery cell testing concept has a great potential for evaluating hybrid vehicle strategies and should also have a potential for evaluating battery management strategies. However, the concept of real life battery cycling is not optimal as a substitute to laboratory battery cycling due to the need for longer test periods. A potential enhancement of the concept would be to increase the number of cycled cells per vehicle, including adding the corresponding number of reference cells. This would improve the robustness of the test regarding potential cell failures, and it would also give additional data for statistical analysis. With this method, it is not possible to obtain exactly the same cell temperature distribution between vehicles, even if active cell heating and cooling is used. It is hence not possible to obtain cell usage at the exact same cell temperature distribution. Using a larger number of vehicles operating in the same region would, on the other hand, minimize the difference in cell temperature distributions between vehicles. The test concept is, however, a relatively cheap way of performing hybrid strategy testing and battery management testing on vehicles.

\section{Acknowledgments}

The authors would like to send their gratitude to Niclas Höök, Olle Gelin, Carl Tengstedt, Ulf Söderberg and Anders Ohlsson for their support during this work. The financial support from Scania CV AB and the Swedish Energy Agency are greatly appreciated.

\section{Author Contributions}

Pontus Svens performed the field tests, lab tests and the data analysis. All authors contributed to the writing of the manuscript, and have read and approved the final manuscript

\section{Conflicts of Interest}

The authors declare no conflict of interest.

\section{References}

1. Mantzos, L.; Capros, P.; Kouvaritakis, N.; Zeka-Paschou, M. European Commission Directorate-General Energy and Transport; Office for Official Publications of the European Communities: Luxembourg, Luxembourg, 2003; p. 149.

2. European Union. Policy Area Transport in More Competitive, Resource-Efficient Transport; European Union: Brussels, Belgium, 2011.

3. Anderson, J.; Fergusson, M.; Valsecchi, C. Policy Department Economic and Scientific Policy; European Union: Brussels, Belgium, 2008; p. 12.

4. European Commision. Europe 2020 Targets; European Union: Brussels, Belgium, 2007. 
5. Tanoue, K.; Yanagihara, H.; Kusumi, H. Hybrid is a key technology for future automobiles. In Hydrogen Technology: Mobile and Portable Applications; Leon, A., Ed.; Springer Science \& Business Media: Karlsruhe, Germany, 2008; pp. 235-272.

6. Matthé, R.; Eberle, U. The voltec system: Energy storage and electric propulsion. In Lithium-Ion Batteries: Advances and Applications; Pistoia, G., Ed.; Elsevier Science: Oxford, UK, 2013; pp. 151-176.

7. Svens, P.; Lindstrom, J.; Gelin, O.; Behm, M.; Lindbergh, G. Novel field test equipment for lithium-ion batteries in hybrid electrical vehicle applications. Energies 2011, 4, 741-757.

8. West Virginia University's Center for Alternative Fuels, Engines and Emissions. Available online: http://cafee.wvu.edu/ (accessed on 2 April 2015).

9. US Environmental Protection Agency. Available online: http://www.epa.gov/ (accessed on 2 April 2015).

10. Svens, P.; Eriksson, R.; Hansson, J.; Behm, M.; Gustafsson, T.; Lindbergh, G. Analysis of aging of commercial composite metal oxide- $\mathrm{Li}_{4} \mathrm{Ti}_{5} \mathrm{O}_{12}$ battery cells. J. Power Sources 2014, 270, 131-141.

11. Du Pasquier, A.; Blyr, A.; Cressent, A.; Lenain, C.; Amatucci, G.; Tarascon, J.M. An update on the high temperature ageing mechanism in $\mathrm{LiMn}_{2} \mathrm{O}_{4}$-based Li-ion cells. J. Power Sources 1999, 81-82, 54-59.

12. Moss, P.L.; Au, G.; Plichta, E.J.; Zheng, J.P. Study of capacity fade of lithium-ion polymer rechargeable batteries with continuous cycling. J. Electrochem. Soc. 2010, 157, A1-A7.

13. Eriksson, T.; Gustafsson, T.; Thomas, J.O. Surface structure of $\mathrm{LiMn}_{2} \mathrm{O}_{4}$ electrodes. Electrochem. Solid State Lett. 2002, 5, A35-A38.

14. Smith, A.J.; Dahn, H.M.; Burns, J.C.; Dahn, J.R. Long-term low-rate cycling of $\mathrm{LiCoO}_{2} /$ graphite Li-ion cells at $55^{\circ} \mathrm{C}$. J. Electrochem. Soc. 2012, 159, A705-A710.

15. Colbow, K.M.; Dahn, J.R.; Haering, R.R. Structure and electrochemistry of the spinel oxides $\mathrm{LiTi}_{2} \mathrm{O}_{4}$ and $\mathrm{Li}_{4} / 3 \mathrm{Ti}_{5} / 3 \mathrm{O}_{4}$. J. Power Sources 1989, 26, 397-402.

16. Ohzuku, T.; Ueda, A.; Yamamoto, N. Zero-strain insertion material of $\mathrm{Li}\left[\mathrm{Li}_{1 / 3} \mathrm{Ti}_{5 / 3}\right] \mathrm{O}_{4}$ for rechargeable lithium cells. J. Electrochem. Soc. 1995, 142, 1431-1435.

17. Bloom, I.; Jansen, A.N.; Abraham, D.P.; Knuth, J.; Jones, S.A.; Battaglia, V.S.; Henriksen, G.L. Differential voltage analyses of high-power, lithium-ion cells: 1. Technique and application. J. Power Sources 2005, 139, 295-303.

18. Dahn, H.M.; Smith, A.J.; Burns, J.C.; Stevens, D.A.; Dahn, J.R. User-friendly differential voltage analysis freeware for the analysis of degradation mechanisms in Li-ion batteries. J. Electrochem. Soc. 2012, 159, A1405-A1409.

19. Honkura, K.; Honbo, H.; Koishikawa, Y.; Horiba, T. State analysis of lithium-ion batteries using discharge curves. ECS Trans. 2008, 13, 61-73.

20. Han, X.; Ouyang, M.; Lu, L.; Li, J.; Zheng, Y.; Li, Z. A comparative study of commercial lithium ion battery cycle life in electrical vehicle: Aging mechanism identification. J. Power Sources 2014, 251, 38-54.

(C) 2015 by the authors; licensee MDPI, Basel, Switzerland. This article is an open access article distributed under the terms and conditions of the Creative Commons Attribution license (http://creativecommons.org/licenses/by/4.0/). 